\title{
SEMENTES RECALCITRANTES: PROBLEMAS NA PÓS-COLHEITA ${ }^{(1)}$
}

\author{
SAMARA CAMARGO LOPES FONSECA ${ }^{(2,4)} ;$ HELENA BARONE FREIRE $^{(3)}$
}

\begin{abstract}
RESUMO
Atualmente, das 6.721 espécies consideradas de importância econômica 7\% possuem sementes que, além de serem sensíveis à dessecação, não toleram armazenamento sob baixas temperaturas, dificultando sua conservação por períodos prolongados. A curta longevidade restringe o prazo de utilização das sementes, sendo necessário realizar a semeadura logo após sua extração dos frutos, ou tentar conserválas sob condições adequadas de temperatura, embalagem e, principalmente, de teor de água; sementes com teores de água acima de $10 \%$ a $13 \%$, a incidência de microorganismos pode comprometer sua viabilidade. Estudos técnico-científicos têm revelado características ecológicas, morfológicas e fisiológicas das sementes recalcitrantes que podem contribuir para o aprimoramento de suas técnicas de propagação. Com base nas informações literárias disponíveis, esta revisão tem por objetivo abordar os principais problemas encontrados após a colheita dessas sementes.
\end{abstract}

Palavras-chave: sementes recalcitrantes, conservação.

\section{ABSTRACT \\ RECALCITRANTS SEEDS: POST-HARVEST PROBLEMS}

At present, $7 \%$ of 6.721 species with some economic importance have seeds that are sensitive to dehydration and do not tolerate storage at low temperatures. The short longevity can reduce the time of seeds utilization, being necessary either to sow then immediately after fruit extraction, or to maintain them under adequate conditions of temperature, storage and water content. Also, seeds with water content above $10 \%-13 \%$ could have the viability reduced by the action of microorganisms. Some studies show ecological, morphological and physiological characteristics of recalcitrant seeds, which can contribute to improve propagation techniques. Therefore based on available literature, this revision was carried out to approach the main problems that can be found after harvesting of recalcitrant seeds.

Key words: recalcitrant seeds, conservation.

${ }^{1}$ ) Recebido para publicação em 4 de setembro de 2002 e aceito em 22 de abril de 2003.

$\left(^{2}\right)$ Doutoranda do Curso de Pós-Graduação em Agronomia-Fitotecnia, Departamento de Produção Vegetal, ESALQ-USP. Caixa Postal 9, 13418-900 Piracicaba (SP). E-mail: saejoe@uol.com.br

$\left({ }^{3}\right)$ Mestranda do Curso de Pós-Graduação em Agronomia-Fitotecnia, ESALQ-USP, Piracicaba (SP). E-mail: hbfreire@esalq.usp.br

$\left({ }^{4}\right)$ Bolsista Capes. 


\section{INTRODUÇÃO}

Na maioria das espécies vegetais de importância econômica, a viabilidade e o vigor das sementes podem ser conservados pela redução do seu teor de água e da temperatura do ambiente. Porém, das 6.721 espécies consideradas $7 \%$ possuem sementes que, além de serem sensíveis à dessecação, não toleram armazenamento sob baixas temperaturas, dificultando sua conservação por períodos prolongados; apresentam importância industrial (seringueira, cacaueiro), florestal (araucária, andiroba, Ingá) e frutífera (abacateiro, mangueira, jaqueira, citros) (Hong e EluIs, 1996). São sementes originárias de árvores perenes dos trópicos úmidos e, em alguns casos, como as de carvalho, de áreas temperadas, diferindo das espécies ortodoxas em sua morfologia, fisiologia e ecologia (CHIN et al., 1989). A maioria das ortodoxas se adapta a campos abertos, sendo provenientes de espécies anuais temperadas (Illy e Viani, 1995, citados por Lima, 2001).

O desenvolvimento fisiológico das sementes ortodoxas pode ser dividido em três fases, sendo a terceira correspondente à desidratação que, resultando na redução gradual do metabolismo, torna o embrião metabolicamente inativo ou quiescente (KERMODE et al., 1989).

Na produção dessas sementes, similarmente ao que ocorre no seu habitat (STUBSGAARD, 1990), a fase de desidratação natural deve coincidir com a estação seca do clima e/ou com a suspensão da irrigação, minimizando os prejuízos à qualidade das sementes (Toledo e Marcos Filho, 1977). Essa fase pode ser interpretada como uma adaptação estratégica das sementes para torná-las aptas a sobreviverem após o armazenamento, além de garantir melhor disseminação das espécies e prover-lhes tolerância às severas condições ambientais, (Leopold, 1990, citado por GuIMARÃES, 2000).

O desenvolvimento das sementes recalcitrantes difere do anterior por não apresentar a fase de desidratação (FARRANT et al., 1988), ou seja, no ponto de maturidade fisiológica ocorre um declínio do teor de água das sementes, sendo, entretanto, não significativo quando comparado à fase de desidratação, propriamente dita, das sementes ortodoxas (KIKUTI, 2000).

Em seu habitat, essas sementes são disseminadas com graus elevados de umidade, em meios úmidos ou durante a estação chuvosa (ROBERTS e KING, 1980), reduzindo a possibilidade de dessecação ou de germinação das sementes na estação seca (STUBSGAARD, 1990). Em igapós amazônicos, por exemplo, sementes de Myrciaria dubia são disseminadas, durante a estação chuvosa, no interior dos frutos suculentos.
Estudos técnico-científicos têm revelado características ecológicas, morfológicas e fisiológicas das sementes recalcitrantes que podem contribuir para o aprimoramento de suas técnicas de propagação. Esta revisão, com base nas informações literárias disponíveis, tem por objetivo abordar os principais problemas encontrados após a colheita dessas sementes.

\section{VIVIPARIDADE}

A ocorrência de germinação das sementes ainda na planta-mãe, comum em algumas espécies recalcitrantes, como as do gênero Ingá, pode estar relacionada com a permanência do teor elevado de água, após a maturação das sementes e/ou com a baixa concentração de substâncias inibidoras presentes no fruto e/ou na própria semente; por exemplo, $80 \%$ das sementes de jaqueira podem germinar no fruto maduro, porém, em cacaueiro, existem substâncias que, sob condições naturais, no fruto e/ou no tegumento das sementes, geralmente inibem a viviparidade (CHIN et al., 1989).

\section{COLHEITA}

A colheita deve ser realizada no ponto de maturidade fisiológica, ou o mais próximo, pois sua elevada atividade metabólica, após a deiscência ou queda dos frutos, pode desencadear o processo germinativo ou favorecer a taxa de deterioração; aliado a isso, a ocorrência de precipitações pluviais intensas pode acentuar significativamente os danos à qualidade, como foi verificado por CICERO et al. (1986) em sementes de seringueira.

$\mathrm{O}$ atraso na colheita pode, ainda, possibilitar a contaminação por microorganismos, contribuindo para a redução do potencial de armazenamento (BARRUeto et al., 1986; Cicero et al., 1986) e/ ou expor as sementes à predação animal. Portanto, a redução do período compreendido entre a deiscência ou queda dos frutos e o início do armazenamento, além de ser fundamental para a manutenção da qualidade das sementes, se faz necessária para minimizar perdas quantitativas.

Por outro lado, a manutenção das sementes nos frutos colhidos por períodos variáveis, antes do beneficiamento, é uma prática que pode evitar a dessecação pós-colheita e preservar o poder germinativo das sementes recalcitrantes (SIMÃo, 1959), devendo, porém, ser utilizada somente em situações de adiantamento da semeadura, devido ao apodrecimento do fruto. 


\section{TOLERÂNCIA À DESSECAÇÃO}

A capacidade fisiológica das sementes em tolerar a dessecação pós-colheita é variável entre as espécies. A maioria possui sementes que toleram dessecação a graus de umidade próximos de $2 \%$ a 5\%, ou mesmo abaixo desses níveis, sendo denominadas ortodoxas. Outras possuem sementes classificadas como "intermediárias" as quais, tolerando dessecação a graus de umidade em torno de $10 \%$ a $13 \%$, têm a viabilidade reduzida em graus de umidade inferiores.

Outro grupo de espécies possui sementes que não toleram dessecação a graus de umidade entre $15 \%$ e $20 \%$, sendo classificadas como recalcitrantes (Roberts, 1973; Hong e Ellis, 1996). Embora, por definição, a secagem de sementes recalcitrantes resulte no declínio da viabilidade, considerável variação na sensibilidade à dessecação tem sido reportada na literatura.

Considerando essa variação, entre outras características, FARRANT et al. (1988) propuseram a separação das sementes recalcitrantes em "altamente", "moderadamente" e "minimamente" recalcitrantes. Certamente, a conservação de sementes recalcitrantes, por longos períodos, não é alcançada com processos similares aos utilizados para as sementes ortodoxas, mormente a secagem. Sem a possibilidade de secagem para a maioria das sementes recalcitrantes, os pesquisadores brasileiros têm mantido elevado o teor de água das sementes através do seu acondicionamento em embalagens herméticas, sob baixas temperaturas (CICERO et al., 1986).

Contudo, tal armazenamento freqüentemente conduz à deterioração das sementes, tanto pelo seu próprio metabolismo, como pelo crescimento de microrganismos favorecido pela umidade. Em algumas espécies, porém, quanto mais cedo e mais rapidamente for realizada a secagem, maior será a tolerância das sementes à dessecação e, com isso, menor será o valor do grau crítico de umidade. No entanto, o processo de secagem lento em sementes de pupunha, em contraste ao rápido, foi favorável à conservação de sua qualidade (FERREIRA e SANTOS, 1993).

$\mathrm{Na}$ secagem das sementes que toleram dessecação parcial devem ser considerados, além do menor grau de umidade de segurança (correspondente ao nível de umidade que pode ser atingido sem prejuízos à viabilidade das sementes) (Hong e ElLIS, 1992), o grau de umidade crítico (abaixo do qual a semente não suporta a secagem) e o grau de umidade letal para cada espécie, já que a variação na sensibilidade à dessecação pode ocorrer, ocasionalmente, entre diferentes lotes da mesma espécie (KING e RoberTs, 1979; EIRA et al., 1994).
Em sementes de Ingá uruguensis, a redução parcial do grau de umidade inicial de $58 \%$ para $49 \%$ possibilitou a conservação do seu potencial fisiológico no armazenamento (BILIA et al., 1998).

A conservação das sementes recalcitrantes pode, ainda, ser obtida com métodos que visem à paralisação ou à limitação do crescimento do eixo embrionário, mantendo a semente em meio suficientemente hidratado para evitar sua desidratação abaixo do teor crítico de água (CHIN et al., 1989). Esse procedimento foi realizado, em sementes de Melicoccus bijugatus, Eugenia brasiliensis (GoLDBACH, 1979) e em Ingá uruguensis (BARBEDO, 1997), empregando-se o ácido abscísico como inibidor da germinação.

Além desse, outros métodos como a estratificação em areia, serragem, carvão ou vermiculita vêm sendo utilizados; conforme observado por SIMÃo (1959), a estratificação em areia foi favorável à manutenção do poder germinativo de sementes de manga no armazenamento.

\section{LONGEVIDADE DAS SEMENTES}

A longevidade corresponde ao período em que a semente se mantém viva, sendo capaz de germinar quando colocada em condições favoráveis, se não for dormente (Toledo e Marcos FILHO, 1977). Uma das primeiras classificações quanto à longevidade, estabelecida em 1908, por Ewart, citado por Hong e ELlis (1996), dividiu as sementes nas categorias microbióticas (longevidade inferior a 3 anos), mesobióticas (longevidade de 3 a 15 anos) e macrobióticas (longevidade superior a 15 anos). HARRINGTON (1972) classificou-as apenas como sementes de vida curta (longevidade inferior a 10 anos) e longevas (longevidade igual ou superior a 10 anos).

Considerando que sua longevidade é relativamente pequena, variando de poucos dias a poucos meses, dependendo da espécie, as sementes recalcitrantes podem ser classificadas como microbióticas ou de vida curta.

A curta longevidade restringe o prazo de utilização das sementes, sendo necessário realizar a semeadura logo após sua extração dos frutos (StubsgaArd, 1990).

Conseqüentemente, além de inviabilizar a instalação de viveiros sob condições climáticas favoráveis à germinação e ao desenvolvimento das mudas, essa limitação pode concentrar a oferta de mudas em determinadas épocas do ano ou ainda, torná-las disponíveis em épocas inadequadas ao plantio. 
A ocorrência de adversidades ambientais entre a formação e a colheita dos frutos, tais como geadas, estiagens e problemas fitossanitários, podem provocar a diminuição na oferta de mudas, em virtude das dificuldades de manutenção de estoques reguladores de sementes.

Pela impossibilidade de formação de mudas em épocas distintas das que são produzidas as sementes em seu habitat, também fica inviabilizada a inclusão de espécies arbóreas tropicais nos programas voltados à recuperação de áreas nativas degradadas (BARBEDO, 1997).

\section{ARMAZENAMENTO}

O armazenamento de sementes constitui-se em um conjunto de procedimentos voltados à preservação de sua qualidade, atuando como instrumento para a formação de estoques reguladores e à manutenção de recursos genéticos por meio de bancos de germoplasma (Aguiar et al., 1993).

No campo, durante a maturação, as deficiências minerais e hídricas do solo e as incidências de pragas e doenças podem impedir as sementes de atingirem a qualidade máxima disponível no potencial genético e, por conseguinte, acelerar a deterioração no armazenamento (PoPIGINIS, 1985).

A velocidade do processo de deterioração pode ser controlada em função da longevidade, da qualidade inicial das sementes e das condições do ambiente; como a longevidade é uma característica genética inerente à espécie, somente a qualidade inicial das sementes e as condições do ambiente de armazenamento podem ser manipuladas (TOLEDO e Marcos Filho, 1977; Popinigis, 1985; Carvalho e NAKAGAWA, 1988).

Durante o armazenamento, a temperatura é um dos fatores ambientais que afeta a longevidade da semente (BASs, 1979). Sementes com elevados teores de água, ortodoxas ou recalcitrantes, são suscetíveis a danos causados por temperaturas negativas, devido à formação de cristais de gelo nos tecidos, provocando perda da viabilidade.

A principal conseqüência disso é a ruptura mecânica, tanto da estrutura citoplasmática quanto da membrana celular, pela expansão da água congelada, resultando na desagregação celular (FUנIKAWA, 1980). Por outro lado, dentro de limites, a redução da temperatura influencia todas as atividades metabólicas das sementes, resultando no melhoramento das condições de armazenamento e, conseqüentemente, na conservação da sua qualidade (Popinigis, 1985).
FerRaz e SAMPAio (1996), estudando sementes de andiroba, testaram procedimentos simples e de ampla aplicação que permitem o armazenamento de sementes recalcitrantes de essências florestais cuja produção de mudas é limitada pela oferta de sementes. Foram testados métodos de armazenamento em sacos plásticos, em diferentes condições ambientais e em água corrente, observando-se o teor de água no início e após os tratamentos.

Os autores notaram que o armazenamento na sombra e o das sementes enterradas no solo não obtiveram sucesso, respectivamente, devido à destruição da embalagem por insetos, o que causou a perda da viabilidade das sementes por desidratação, e à destruição dos sacos pela fauna do solo, o que favoreceu a embebição e, conseqüentemente, a germinação das sementes. Além disso, as sementes de andiroba não suportaram o armazenamento em água corrente, nem em condições de temperaturas baixas $\left(6^{\circ} \mathrm{C} \pm 4{ }^{\circ} \mathrm{C}\right)$. $\mathrm{O}$ armazenamento, durante sete meses, manteve a viabilidade das sementes em sacos plásticos selados somente quando realizado em ambiente com arcondicionado $\left(25^{\circ} \mathrm{C} \pm 4{ }^{\circ} \mathrm{C}\right.$ e $45 \%$ a $60 \%$ UR).

Gentil (1999) verificou a influência da temperatura de armazenamento e do grau de umidade de sementes de café na manutenção da sua qualidade. Sementes com $51 \%, 41 \%, 34 \%, 23 \%, 16 \%$ e $10 \%$ de água, acondicionadas em sacos de polietileno e mantidas sob temperaturas de 30,20 e $10{ }^{\circ} \mathrm{C}$, durante 48 semanas de armazenamento, foram submetidas às avaliações fisiológicas e sanitárias periódicas. $\mathrm{O}$ autor concluiu que a redução do grau de umidade até $10 \%$ e da temperatura até $10^{\circ} \mathrm{C}$ foi a combinação mais favorável à manutenção da qualidade das sementes durante $\mathrm{o}$ armazenamento.

Os resultados científicos, obtidos a respeito da conservação de sementes recalcitrantes, entretanto, ainda são contraditórios. Conforme FARRANT et al. (1988), as sementes "altamente" e "moderadamente" recalcitrantes apresentam maior tolerância a baixas temperaturas, porém nunca igual ou inferior a $0{ }^{\circ} \mathrm{C}$; temperaturas iguais ou inferiores a $15^{\circ} \mathrm{C}$ não são favoráveis ao armazenamento de sementes de cacau (Hor et al., 1984), de pupunha (Villalobos et al., 1992), de seringueira (CICERO et al., 1986) e de mangueira (Fu et al., 1990); as sementes de abacate e de pitanga, no entanto, toleram temperaturas de 3 a $4{ }^{\circ} \mathrm{C}$ e as de Inga edulis, temperatura de $0{ }^{\circ} \mathrm{C}$ (BACCHI, 1961). Segundo ElLIS et al. (1990, 1991a,b), sementes de mamão, café e dendê, quando desidratadas entre $8 \%$ e $10 \%$ graus de umidade e armazenadas sob temperaturas próximas e abaixo de zero, apresentaram perda do poder germinativo durante armazenagem, mesmo sendo classificadas como "intermediárias" quanto ao comportamento. 
Em sementes com teores de água acima de 10\% a 13\%, a incidência de microrganismos pode comprometer sua viabilidade (HARRINGTON, 1972). A ocorrência de fungos constitui um dos principais fatores prejudiciais à conservação das sementes recalcitrantes, geralmente armazenadas úmidas sob temperaturas acima de $0{ }^{\circ} \mathrm{C}$ (Goldbach, 1979).

Alguns fungos de campo, como os do gênero Rhizopus, Alternaria, Mucor, Cladosporium e Nigrospora, e de armazenamento, como os do gênero Penicillium e Aspergillus, têm sido observados em associação com sementes recalcitrantes armazenadas (GOMIDE et al., 1994); os estudos, entretanto, não conseguiram aferir com exatidão os efeitos da incidência desses fungos sobre a qualidade fisiológica das sementes.

Uma alternativa para diminuir a incidência de microrganismos em sementes recalcitrantes seria a redução da temperatura do ambiente de armazenamento; como já mencionado, porém, essa não é uma prática adequada para a maioria dessas sementes (KING e ROBERTS, 1979).

Outra opção seria a aplicação de fungicidas, pois, de acordo com FigueIREDO (1986), as sementes de cacaueiro tratadas conservaram-se mais adequadamente, durante períodos prolongados, do que as não tratadas. Algumas espécies, entretanto, podem apresentar maior sensibilidade à fitotoxidade de fungicidas, como observado em sementes de seringueira tratadas com benlate, captan e thiran (CiCERO et al., 1986; GARCIA e Vieira, 1994).

A germinação no armazenamento pode representar perdas significativas na conservação de sementes recalcitrantes quando mantidas úmidas sob temperaturas inadequadas (KING e RoBERTS, 1979). A condição úmida favorece a germinação, podendo levar a um estresse hídrico que causaria danos oxidativos pela ação de radicais livres (Pammenter et al., 1994, citados por BARbedo e Cícero, 2000); a dormência, sob tal condição, facilitou o armazenamento de sementes de abacate, manga (AroeIrA, 1962) e araçá-boi (GENTIL e FerReIRA, 1999), prevenindo a germinação. No entanto, a ausência de dormência em sementes "altamente" recalcitrantes implica a necessidade do desenvolvimento de métodos alternativos para prevenir a germinação durante o armazenamento, como por exemplo, o uso de substâncias inibidoras como ABA e PEG (GoldBACH, 1979).

De acordo com BEWLEY e BLACK, (1985), apenas concentrações elevadas de ácido abscísico (ABA), fornecidas artificialmente, inibem o desenvolvimento do eixo embrionário. A aplicação exógena de $\mathrm{ABA}$, em sementes recalcitrantes, além de estimular o acúmulo de proteínas de reserva, resulta em inibição mais evidente da germinação do que a causada pelos níveis internos de ABA das sementes.
Durante a maturação, entretanto, não só o nível de ABA decresce, como também a sensibilidade da semente às aplicações exógenas diminui (Zeevaart e Creelman, 1988; Fincher, 1989 citados por BARBEDO, 1997). Em sementes de Sesbania marginata, aplicações exógenas de $\mathrm{ABA}$, nas concentrações de $10^{-4} \mathrm{M}$ e 10 $M$, retardaram e inibiram, respectivamente, a germinação. Uma vez utilizado um eficiente método de identificação da qualidade fisiológica das sementes, juntamente com a combinação de baixa temperatura e a correta concentração de ácido abscísico, foi possível conservar sementes de Inga uruguensis por aproximadamente dois meses (BARBEDO e Cí́cero, 2000).

As embalagens utilizadas no armazenamento exercem importante papel na manutenção do vigor inicial das sementes (CARNEIRO, 1987). Como a conservação das sementes recalcitrantes depende da manutenção do seu teor de água em níveis elevados e constantes, a escolha da embalagem está relacionada, principalmente, à umidade relativa do ar sob as quais as sementes ficarão armazenadas.

Em ambientes saturados de umidade, as sementes poderão ser armazenadas a granel ou em embalagem permeável ao vapor d'água; caso contrário, deverão ser mantidas em embalagem impermeável, visando eliminar a influência da umidade relativa do ar externo no ambiente interno e, por conseguinte, as alterações no seu teor de água.

No armazenamento de sementes úmidas, o suprimento de oxigênio é essencial à respiração, que produzirá energia metabólica necessária à ativação e sustentação de mecanismos de reparo e de substituição celular, tendo como conseqüência a ampliação do período de conservação (KING e RoberTs, 1979). Paralelamente, deve-se evitar o acúmulo de gás carbônico, por ser prejudicial à qualidade fisiológica das sementes (Toledo e Marcos Filho, 1977).

O emprego de sacos de polietileno, com 0,1 $\mathrm{mm}$ de espessura, para permitir troca gasosa suficiente entre as sementes e o ambiente externo, minimizando a perda de água das sementes, apresentou resultados satisfatórios no armazenamento de sementes de abacateiro e de seringueira (BONNER, 1978).

No mercado, entretanto, existem tipos de películas de polietileno à venda que, variando quanto à espessura e densidade, apresentam diferentes níveis de resistência à entrada/saída de vapor d'água e de gases (Toledo e Marcos FilHo, 1977). Ademais, podem ocorrer variações na espessura e na densidade da mesma embalagem, principalmente se for feita com material reciclado. Usualmente, as espécies que apresentam sementes recalcitrantes são conservadas $e x$ situ, isto é, em campo ou em casa de vegetação, o que é extremamente caro e laborioso. 
Da mesma maneira, populações com elevada heterozigose, coleções de plantas com períodos juvenis longos, plantas cujas sementes são produzidas em pouca quantidade e/ou com viabilidade reduzida, ou quando se conservam por pouco tempo, são mantidas vegetativamente (TowILL, 2000).

Segundo Andrade e Pereira (1997), as sementes recalcitrantes de palmito necessitam de pesquisas para conservação $e x$ situ mais eficiente da espécie, pois as técnicas convencionais de armazenagem utilizadas em bancos de germoplasma-semente não são satisfatórias. Entretanto, atualmente, as tecnologias ditas in vitro representam estratégias importantes para a conservação de sementes recalcitrantes: culturas de embriões zigóticos e eixos embrionários isolados, derivados de sementes maduras, normalmente sobrevivem à dessecação parcial e ao congelamento, da mesma forma que ápices caulinares e gemas podem ser criopreservados (TowILL, 2000).

\section{CONSIDERAÇÕES FINAIS}

Uma vez que somente as sementes ortodoxas podem ser conservadas por longos períodos sem perderem a viabilidade, a identificação correta do comportamento de armazenagem de uma espécie se faz necessária para a escolha da estratégia de sua conservação, sendo o teor de água das sementes um fator crítico nessa identificação.

A perda de água em sementes recalcitrantes desencadeia alguns processos deterioráveis, como a desnaturação de proteínas, alterações na atividade das enzimas peroxidases e danos no sistema de membranas, resultando na completa perda de sua viabilidade (Nautiyal e Purohit, 1985). Dessa maneira, se faz necessário aprimorar o conhecimento científico sobre seus mecanismos fisiológicos, relacionados à sensibilidade, à dessecação e às baixas temperaturas, para determinar métodos eficientes de armazenagem das sementes.

\section{AGRADECIMENTOS}

Ao Professor Dr. Silvio Moure Cicero (ESALQUSP), ministrante da disciplina Produção de Sementes, em que este trabalho foi um dos requisitos de avaliação.

\section{REFERÊNCIAS BIBLIOGRÁFICAS}

AGUIAR, I.B.; PINA-RODRIGUES, F.C.M.; FIGLIOLIA, M.B. Sementes florestais tropicais. Brasília: ABRATES, 1993. 350p.
ANDRADE, A.C.S. ; PEREIRA, T.S. Comportamento de armazenamento de sementes de palmiteiro. Pesquisa Agropecuária Brasileira, Brasília, v.32, n.10, 1997.

AROEIRA, J.S. Dormência e conservação de sementes de algumas plantas frutíferas. Experientiae, Viçosa, v.2, n.3, p.541-609, 1962.

BACCHI, O. Estudos sobre a conservação de sementes. XI. Ingá. Bragantia, Campinas, v.20, n.35, p.805-814, 1961.

BARBEDO, C.J. Armazenamento de sementes de Ingá uruguensis Hook. \& Arn. 1997. 71f. Tese (Doutorado) - Escola Superior de Agricultura Luiz de Queiroz, Piracicaba.

BARBEDO, C.J.; CICERO, S.M. Effects of initial quality, low temperature and ABA on the storage of seeds of Ingá uruguensis, a tropical species with recalcitrant seeds. Seed Science and Tecnology, Zurich, v.28, p.793-808, 2000.

BARRUETO, L.P.; PEREIRA, I.P.; NEVES, M.A. Influência da maturação fisiológica e do período entre a coleta e o início do armazenamento, sobre a viabilidade da semente de seringueira. Turrialba, San José, v.36, n.1, p.65-75, 1986.

BASS, L.N. Physiological and other aspects of seed preservation. In: RUBENSTEIN, I.; PHILLIPS, R.L.; GREEN, C.E.; GENGENBACH, B.G. The plant seed: development, preservation and germination. New York: Academic Press, 1979. p.145-170.

BEWLEY, J.D.; BLACK, M. Seeds: physiology of development and germination. New York: Plenum Press, 1985.

BILIA, D.A.C.; MARCOS FILHO, J.; NOVEMBRE, A.D.L.C. Conservação da qualidade fisiológica de sementes de Ingá uruguensis. Revista Brasileira de Sementes, Brasília, v.20, n.1, p.4854, 1998.

BONNER, F.T. Storage of hardwood seeds. Forest Genetic Resources Information, Rome, n.7, p.10-17, 1978.

CARNEIRO, J.G.A. Armazenamento de sementes florestais. Curitiba: FUPEF, 1987. 35p.

CARVALHO, N.M.; NAKAGAWA, J. Sementes: ciência, tecnologia e produção. 3.ed. Campinas: Fundação Cargill, 1988. 424p.

CHIN, H.F.; HOR, Y.L.; LASSIM, M.B. Identification of recalcitrant seeds. Seed Science and Technology, Zurich, v.12, p.429-436, 1989.

CICERO, S.M.; MARCOS FILHO, J.; TOLEDO, F.F. Efeitos do tratamento fungicida e de três ambientes de armazenamento sobre a conservação de seringueira. Anais da ESALQ, Piracicaba, v.43, n.2, p.763-787, 1986.

EIRA, M.T.S.; SALOMÃO, A.N.; CUNHA, R.; CARRARA, D.K.; MELLO, C.M.C. Efeito do teor de água sobre a germinação de sementes de Araucaria angustifolia. Revista Brasileira de Sementes, Brasília, v.16, n.1, p.71-75, 1994.

ELLIS, R.H.; HONG, T.D.; ROBERTS, E.H. An intermediate category of seed storage behaviour? I. Coffee. Journal of Experimental Botany, Oxford, v.41, n.230, p.1167-1174, 1990. 
ELLIS, R.H.; HONG, T.D.; ROBERTS, E.H. Effect of temperature and moisture content on the germination of papaya seeds. Seed Science Research, California, v.1, p.69-72, 1991a.

ELLIS, R.H.; HONG, T.D.; ROBERTS, E.H.; SOETISNA, U. Seed storage behaviour in Elaeis guineensis. Seed Science Research, Califórnia, v.1, p.99-104, 1991b.

FARRANT, J.M.; PAMMENTER, N.W.; BERJAK, P. Recalcitrance: a current assessment. Seed Science and Technology, Zurich, v.16, p.155-166, 1988.

FERRAZ, I.D.K.; SAMPAIO, P.T.B. Métodos simples de armazenamento das sementes de andiroba (Carapa guianensis Aubl. e Carapa procera D.C. Meliaceae). Acta Amazonica, Manaus, v.26, n.3, p.137-144, 1996.

FERREIRA, S.A.N.; SANTOS, L.A. Efeito da velocidade de secagem sobre a emergência e vigor de sementes de pupunha. Acta Amazonica, Manaus, v.23, n.1, p.3-8, 1993.

FIGUEIREDO, S.F.L. Conservação da viabilidade da semente de cacau. IV. Efeito de fungicidas e peletização. Theobroma, Ilhéus, v.16, n.4, p.173-188, 1986.

FU, J.R.; ZHANG, B.Z.; WANG, X.P.; QIAO, Y.Z.; HUANG, $X . L$. Physiological studies on desiccation, wet storage and cryopreservation of recalcitrant seeds of three fruit species and their excised embryonic axes. Seed Science and Tecnology, Zurich, v.18, p.743-754, 1990.

FUJIKAWA, S. Freeze-fracture and etching studies on membrane damage on human erythrocytes caused by formation of intracellular ice. Cryobiology, Espanha, v.17, p.351362, 1980.

GARCIA, A.; VIEIRA, R.D. Germinação, armazenamento e tratamento fungicida de sementes de seringueira. Revista Brasileira de Sementes, Brasília, v.16, n.2, p.128-133, 1994.

GENTIL, D.F.O. Conservação de sementes de Coffea arabica L.: interferências do grau de umidade e da temperatura. 1999. 41f. Dissertação (Mestrado) - Escola Superior de Agricultura Luiz de Queiroz, Piracicaba.

GENTIL, D.F.O.; FERREIRA, S.A.N. Viabilidade e superação da dormência em sementes de araçá-boi. Acta Amazonica, Manaus, v.29, n.1, p.21-31, 1999.

GOLDBACH, H. Imbibed storage of Melicoccus bijugatus and Eugenia brasiliensis using abscisic acid as a germination inhibitor. Seed Science and Technology, Zurich, v.7, p.403-406, 1979.

GOMIDE, C.C.C.; FONSECA, C.E.L.; NASSER, L.C.B.; CHARCHAR, M.J.D.; FARIAS NETO, A.L. Identificação e controle de fungos associados às sementes armazenadas de cagaita. Pesquisa Agropecuária Brasileira, Brasília, v.29, n.6, p.885-890, 1994.

GUIMARÃES, R.M. Tolerância à dessecação e condicionamento fisiológico em sementes de cafeeiro (Coffea arabica, L.). 2000. $180 \mathrm{f}$. Tese (Doutorado) - Universidade Federal de Lavras.

HARRINGTON, J.F. Seed storage and longevity. In: KOZLOWSKI, T.T. Seed biology: insects, seed collection, storage, testing and certification, v.3. New York: Academic Press, 1972. cap.3, p.145-245.

HONG, T.D.; ELLIS, R.M. Optimum air-dry seed storage enviroments for arabica coffe. Seed Science and Tecnology, Zurich, v.20, p.547-560, 1992.

HONG, T.D.; ELLIS, R.H. A protocol to determine seed storage behavior. In: ENGELS, J.M.M; TOLL, J. Rome: IPGRI, 1996. 62p. (IPGRI Technical Bulletin n.1)

HOR, Y.L.; CHIN, H.F.; KARIM, M.Z. The effect of seed moisture and storage temperature on the storability of cocoa seeds. Seed Science and Technology, Zurich, v.12, n.2, p.415-420. 1984.

KERMODE, A.R.; OISHI, M.Y.; BEWLEY, J.D. Regulatory roles for desiccation and abscisic acid in seed development: a comparison of the evidence from whole seeds and isolated embryos. In: STANWOOD, P.C.; McDONALD, M.B. Seed moisture. Madison: CSSA, p.23-50, 1989.

KIKUTI, A.L.P. Aplicação de antioxidantes em sementes de cafeeiro visando à preservação da qualidade. 2000. 72f. Dissertação (Mestrado) - Universidade Federal de Lavras.

KING, M.W.; ROBERTS, E.H. The storage of recalcitrant seeds: achievements and possible approaches. Rome: IBPGR, 1979. 96p.

LIMA, S.M.P. Condicionamento fisiológico de sementes de cafeeiro: efeitos na germinação, vigor e formação de mudas. 2001. 161f. Dissertação (Mestrado) - Universidade Federal de Lavras.

NAUTIYAL, A.R.; PUROHIT, A.N. Seed viability in sal. II. Physiological and biochemical aspects of ageing in seeds of Shorea robusta. Seed Science and Technology, Zurich, v.13, p.6976, 1985.

POPINIGIS, F. Fisiologia da semente. Brasília: [s.n.], 1985. 289p.

ROBERTS, E.H. Predicting the storage life of seeds. Seed Science and Tecnology, Zurich, v.1, p.499-514, 1973.

ROBERTS, E.H.; KING, M.W. The characteristics of recalcitrant seeds. In: CHIN, H.F.; ROBERTS, E.H. Recalcitrant crop seeds. Kuala Lumpur: Tropical Press, 1980. p.1-5.

SIMÃO, S. Estudo do poder germinativo da semente de manga. Anais da ESALQ, Piracicaba, v.16, p.289-297, 1959.

STUBSGAARD, F. Seed moisture. Humlebaek: DFSC, 1990.30p.

TOLEDO, F.F.; MARCOS FILHO, J. Manual de sementes: tecnologia da produção. São Paulo: Agronômica Ceres, 1977. 224p.

TOWILL, L.E. Germplasm preservation. In: TRIGIANO R.N.; GRAY D.J. Plant tissue culture concepts and laboratory exercises. 2.ed. Boca Raton: CRC Press, 2000. p.337-353

VILLALOBOS, R.; HERRERA, J.; MORA-URPI, J. Germinacion de la semilla de pejibaye. III. Efecto del contenido de agua y de las condiciones de almacenamiento. Agronomica Costarricense, San José, v.16, n.1, p.69-76, 1992. 